\title{
JOAQUINA GARCÍA BALMASEDA: UNA ESCRITORA ISABELINA AL SERVICIO DE LA MUJER
}

\author{
Dolores THION SORIANO-MOLLÁ \\ Université de Pau et des Pays de l'Adour
}

\section{RESUMEN}

Joaquina García Balmaseda (1837-1911) fue una escritora polígrafa que consagró toda su vida a la cuestión social femenina. Aunque vivió inmersa en el neocatolisicmo imperante durante la época de Isabel II, la escritora abrió importantes brechas, todas ellas relativas a la educación de la mujer como pilar de la célula familiar, pero también como medio para garantizar a la mujer soltera buenas condiciones de vida, su independencia y su libertad. Su propia trayectoria personal así lo demostró.

Palabras clave: Joaquina García Balmaseda, escritora, periodista, traductora, siglo XIX, cuestión femenina, Educación, familia.

\begin{abstract}
Joaquina García Balmaseda (1837-1911) was a polygraph writer who devoted her entire life to the social condition of women. Although she lived in an era when neocatholic values still prevailed, during the reign of Queen Isabel II, she managed to raise the question of female education not only as a way to maintain the cohesion of the family unit, but also as a means to make sure that unmarried women are able to live a free and independent existence in safe and sound conditions. Her own life is a good illustration of this.
\end{abstract}

Key words: Joaquina García Balmaseda, writer, journalist, translator, 19th Century, feminine question, education, family. 
Entre las escritoras decimonónicas que han empezado a salir puntualmente del olvido destaca la figura de Joaquina García Balmaseda, a quien se le han consagrado varios trabajos, en particular, sobre su obra teatral (Caldera, 1990; Gies, 1996; Smith, 2009) y de quien se han ido recuperando algunos artículos sobre la cuestión femenina olvidados en las páginas de la prensa (Simón Palmer, 1891; Blanco, 1998 y 2001; Sánchez Llama, 2001). Pero su femenina pluma no sólo se ejerció en esos campos. La señorita Balmaseda, como se la solía denominar, desarrolló una prolífica actividad: manuales instructivos y morales, poesías, cuentos e innumerables colaboraciones periodísticas de índole diversa fueron viendo la luz durante su trayectoria vital, más longeva de lo que hasta la fecha se ha sostenido.

Pocos datos se disponen de García Balmaseda. Hija de una familia humilde, de Dámaso García Fernández y de Francisca Balmaseda Olivares, doña Joaquina nació el 17 de febrero de 1837 en Madrid. Estudió declamación en el Conservatorio y trabajó de actriz durante sus años de juventud. Formó parte de la compañía de Joaquín Arjona, en la que «logró durante cuatro años abundantes cosechas de aplausos» (C. B., 1894: 14).

A partir de 1857 su firma empezó a aparecer en la prensa, medio en el que desarrolló una fecunda labor durante casi cuarenta años, intentando «llenar el vacío» (García Balmaseda, 1860: 4) que en España acusaba la educación femenina ${ }^{1}$. Con su infatigable quehacer contribuyó, como Gertrudis Gómez de Avellaneda, Carolina Coronado, Faustina Sáez de Melgar, Ángela Grassi o Pilar Sinués, por citar algunas escritoras isabelinas, a la paulatina transformación de las mentalidades, imprescindible para que la situación de la mujer española evolucionase. En términos de satisfacción lo debió de constatar, cuando tras largos años de entrega a las Letras y de presencia en la esfera pública, la escritora escribía:

Mucho ha ganado la mujer en general en la última mitad de este siglo; la sociedad que ridiculizaba a la poetisa y que menospreciaba a la cómica, que no consentía a la mujer pintora, y menos todavía erudita, concede a la escritora consideraciones, se honra con la amistad de las actrices que son dignas de su amistad en su vida privada, admite a la mujer en certámenes de pintura y

1. Porque, como declaraba en 1860, mientras en Francia, Inglaterra y Alemania y otros países se concedía a la educación de las niñas suma importancia, en España, «si bien algún escritor distinguido se ha ocupado de la mujer, ha sido tan solo para ensalzarla o deprimirla, según él lo deseaba o comprendía, y si alguna vez se le han dirigido consejos morales, apenas hay quien se haya tomado el trabajo de guiarla por los detalles de la vida familiar, tan necesarios para llegar a ser un día buena esposa y buena madre» (García Balmaseda, 1860: 4). 
crea para ellas academias e institutos. ¡Qué gran paso en la civilización social! (García Balmaseda, [1884]: 74).

Estas declaraciones, que probablemente datan de 1881, resumirían perfectamente la trayectoria de esa «civilización social» y de la misma actriz y polígrafa en su contexto socio-histórico. Ahora bien, el acceso a la educación para todas las mujeres, la profesionalización de algunas de ellas y lo que ello conllevaba en el acceso a la esfera pública, lo supeditaba García Balmaseda a cada mujer y su circunstancia fuese cual fuese su clase social, otorgándole, cuando alcanzaba cierto grado de instrucción y educación moral, un margen de libertad e independencia. Todo ello sin salirse de los moldes del neocatolicismo, con la firme creencia en la misión a la que Dios la ha destinado con su carácter y sus cualidades en el seno de la sociedad, en primer término doméstica y familiar, en segundo profesional, sin que una excluyese a la otra, sin que el matrimonio o la maternidad fuesen las únicas vías para alcanzar la felicidad. Su propia experiencia vital y su personal trayectoria influyeron, como estudiaremos, en estas pequeñas brechas con las que la escritora empezó a abrir fisuras en el mundo cerrado del ángel del hogar.

En 1857, Joaquina García Balmaseda lanzó sus primeras armas en el mundo de las Letras como asidua colaboradora en La Educación Pintoresca, un periódico para jóvenes y niños. La periodista pronto pudo diversificar su público lector a través de las numerosas cabeceras que surgieron con el auge de la prensa. Revistas y periódicos se convirtieron en un objeto de consumo más popular y mejor difundido, por lo que proliferaron las dirigidas al sector femenino por motivos comerciales. En ellas colaboró Doña Joaquina, en particular, en La Floresta de (Barcelona 1857), en El Museo de las Familias (1861), en La Aurora de la vida (1861), en La América (1861y 1867), en La Educanda (1862-1865), en El Museo Literario (Valencia, 1863-1866) y en La Violeta (1864). En estas hojas volanderas Joaquina García Balmaseda publicó artículos, fábulas y cuentos educativos y recreativos para niños, jóvenes y mujeres en función de las cabeceras. Los textos solían ser breves. Eran sencillas ficciones con moraleja y, a menudo, acompañaban la lámina o el figurín que las publicaciones intercalaban. La finalidad de estas contribuciones obedecía a la máxima horaciana, enseñar deleitando. Desarrollar la curiosidad, instruir y educar moral y religiosamente a mujeres, niños y jóvenes con la firme voluntad de suplir un sistema educativo deficiente o la ignorancia en las familias menos hacendadas, asignó a este tipo de literatura fines y méritos de altos vuelos. A partir de 1860 la escritora logró integrar el equipo de colaboradores del diario nacional La Correspondencia de España, redacción en la que permaneció en los momentos de mayor auge de este periódico hasta avanzada la 
década de los 80 , publicando artículos, traducciones de novelas y crónicas, en particular, sobre la moda. En él fue responsable de la sección literaria a partir de 1864. El notable número de novelas que tradujo del francés, del italiano y del inglés para publicarlas en folletines por entregas en aquel periódico la convierten en una de las más eficaces introductoras y vulgarizadoras de la novela, sobre todo francesa, en España ${ }^{2}$. Durantes estos primeros diez de intensa actividad, el carácter poligráfico de la escritora se confirmó además con la publicación en 1868 de una antología poética, Entre el cielo y tierra, acompañada del prólogo de Manuel Cañete ${ }^{3}$, de algunos manuales pedagógicos y varias piezas breves de teatro.

Si bien su presencia constante en la prensa determinó su expedita nombradía, fue su actividad como pedagoga la que la consagró, desde aquellas letras de molde, pero sobre todo, por el éxito y la gran difusión que alcanzaron sus manuales para la educación moral y la instrucción de niñas y mujeres. En junio de 1860 salió a la luz La madre de familia, obra que fue seleccionada como libro de lectura en las escuelas de primera enseñanza ${ }^{4}$. Se trata de una colección, como reza el subtítulo, de Diálogos instructivos sobre la religión, la moral y las maravillas de la naturaleza. Era una especie de manual de socialización familiar destinado a concienciar a las mujeres a través de una sencilla ficción, la de una viuda que sabe aprovechar cualquier circunstancia de la vida para ir educando a sus hijos. La escritora recreaba con ajustado realismo

2. En La Correspondencia de España publicó las traducciones de: La dicha de ser rico, de Henri Consciente; El Crimen de Orcival, El dinero de los otros, El legajo núm. 113, El proceso Lerouge, La canalla dorada, Los esclavos de Paris, y Los secretos de la casa Champdoce, de Emilio Gaboriau; Amada, El caballero Fortuna, El paraíso de las mujeres, y El pretil de aventureros, de Paul Feval; Dos madres, El conde de Coulange, La encantadora, y La hija maldecida, de Emilio Richebourg; Cesarina Dietrich, El marqués de Villemer, y Flamarandre, de Jorge Sand; El coche número 13, El médico de las locas, y El secreto de la Condesa, de Javier de Montepín; La hada de Auteuil, Los amores de Aurora, y Los misterios de una raza, de Ponson da Terrail; La muerta viva, Marido y mujer, y Pobre Lucila, de Wilkie Collins; Cecilia, y Creación y redención, de Alejandro Dumas; Diario de una mujer, de Octavio Feuillet, Dos miserias, de Emilio Souvestre; El abismo, de Carlos Dickens; El beso de la Condesa Sabina, de A. Gaccianiga; El caballero de Pampelonne, de Arístides de Gondtecour, El capitán del buitre, de Mary E. Braddon; El padre de Marcial, de Alberto Delpit; El prometido de Simona, de Víctor Cherbulier; El renegado, de Claretie; El vampiro de Valdegracia, de León Gozlen; Fremont joven y Risler mayor, de Alfonso Daudet; La novia, de Enmanuel González; Los amores de una gran señora, de Alfredo de Brehat; Los malvados, de Tortunato de Boisgobey; Madama Frainex, de Roberto Halt; Santiago Broneau, de Madame de Clesinger; Sergio Panine de Jorge Ohnet, y Un estreno en la Opera, de Ernesto Feydeau. (Huerta Posada, 14 de junio de 1896: 262).

3. Fue reseñada elogiosamente por el prologuista (Manuel Cañete,1868).

4. Por las Reales Órdenes de 1 de junio de 1861 y del 1 de noviembre de 1863 . Fue reeditada varias veces 
las conversaciones que la madre o un amigo de la familia iban manteniendo con los niños, engarzando temas diversos con bastante naturalidad. Los temas propuestos eran básicos, una heterogénea mezcolanza entre catequesis, religión, ciencias naturales, geografía, historia, higiene, labores, economía doméstica y estudios de adorno. Para la escritora, estos últimos, es decir, el dibujo, la música, la poesía y los idiomas complementaban los anteriores, pero en ningún caso debían suplirlos como solía ocurrir en la educación de algunas jóvenes de la alta sociedad. Eran útiles para «desarrollar vuestra inteligencia», explicaba la ficticia señora de Álvarez a sus hijos, pero además, «os harán ser apreciables en sociedad, embelleciendo además las horas de vuestra vida» (García Balmaseda, 1860b:155). Ya entonces, y pese a los rígidos moldes dominantes, doña Joaquina empezó a introducir, siempre de manera conciliadora, otras alternativas para la mujer. Como era habitual en la época, el documento histórico se erigía en verdad fehaciente, en dato convincente, aunque singular, para sumar nuevas disyuntivas y para añadir, sin suplantar, otros rasgos que también podían ser femeninos, otras funciones que también podían ser sociales y públicas. En el extenso capítulo titulado «Mujeres célebres» iba proponiendo a sus tiernas lectoras breves retratos de las mujeres más famosas de la historia y de la Biblia. Las figuras históricas le permitían a la escritora concienciarlas de que «las mujeres pueden valer tanto como los hombres, y adquirir como ellos celebridad» (García Balmaseda 1860b: 119). Aun cuando sea «la constitución de la mujer, más delicada» (García Balmaseda, 1860b: 118), sus respectivos destinos son «iguales en importancia», dentro o fuera del hogar, a condición que "por ellos no abandone sus primitivas y naturales ocupaciones; y algunas ha habido que, con inteligencia superior a la de muchos hombres, han dado días de gloria a su país, alcanzando para su nombre la inmortalidad» (García Balmaseda, 1860b: 119).

En un país fundamentalmente analfabeto e inculto, lo urgente era que la mayoría de las mujeres se convirtiesen en buenas madres, esposas y amas de casa, y ella en estos años fue una escritora para las mayorías. Al margen de la escuela, Joaquina García Balmaseda estaba convencida de que la educación podía asimismo obtenerse por medio de la lectura útil y los medios de comunicación a la sazón masivos: la prensa, cada vez más accesible a las clases bajas, y el teatro breve con valores y enseñanzas morales.

En el contexto neocatólico isabelino, las perspectivas del feminismo de Joaquina García Balmaseda, al igual que numerosas coetáneas suyas, concilian moral, religiosidad y evolución de la mujer. Estos tres factores sirven de referente y medida para acuñar un modelo de mujer, a primera vista, más tradicional que nuevo. Siendo Dios guía y Padre, la mujer tiene, a juicio de 


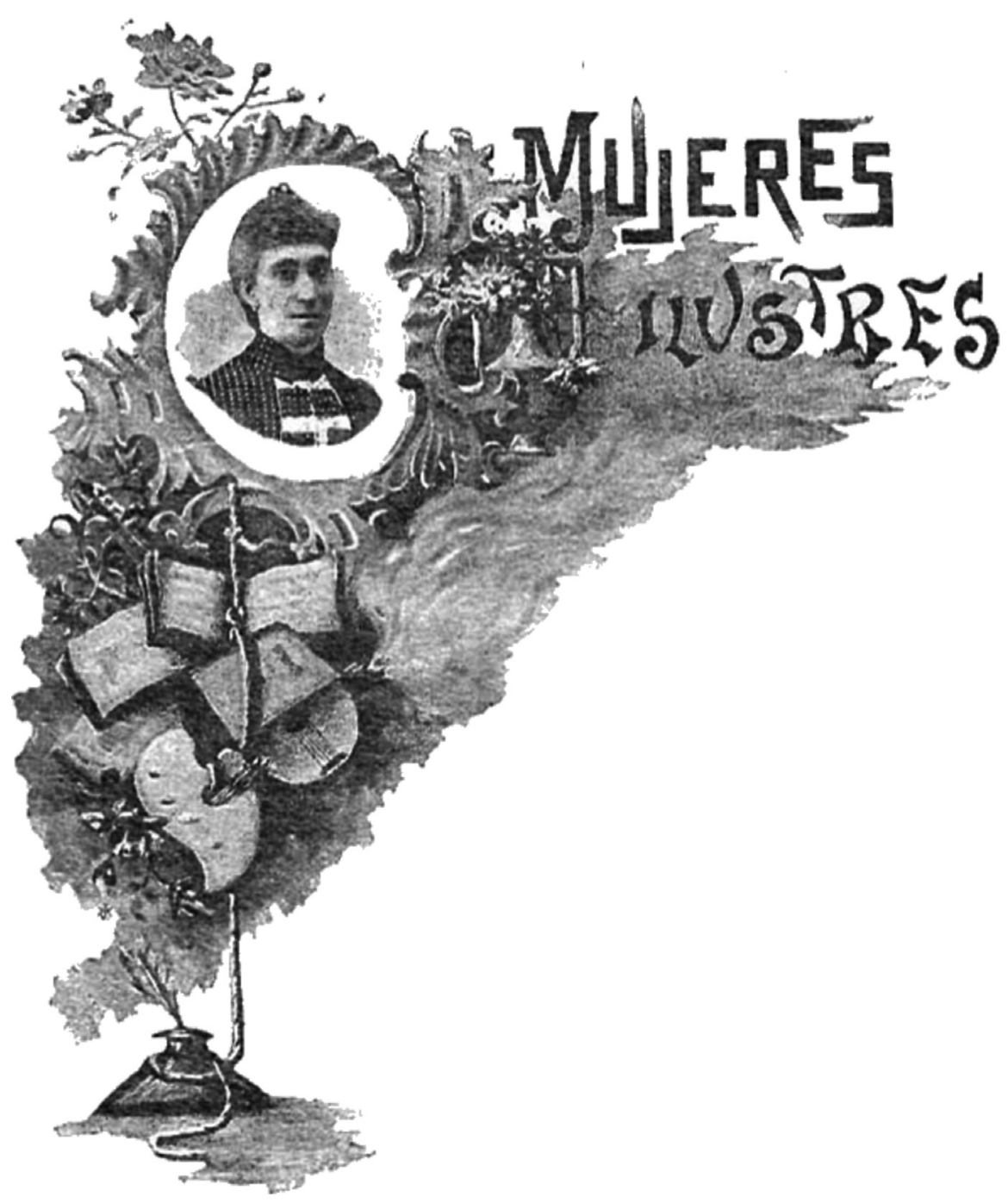

Joaquina Balsameda (Barcelona Cómica, 10 de marzo de 1894)

Doña Joaquina, que respetar la misión «noble y bella» que éste le ha confiado, como persona complementaria al hombre en sus inclinaciones y temperamento, pero asimismo por sus naturales «afectos tranquilos, sentimientos dulces, aspiraciones modestas, ocupaciones sencillas» (García Balmaseda, 1860a: 3) que Dios le encomienda; es decir, en un ámbito de la domesticidad considerado como el propio y natural: 
Ella es en la vida tempestuosa del hombre el puerto seguro de paz y de ventura: en el hogar doméstico el ángel tutelar que guarda y economiza la hacienda, vela el sueño del padre o del esposo, forma el corazón del niño dirigiendo sus primeros pasos por la senda del bien, y hasta en sus horas de recreo se ocupa, trabaja y vive para su familia. ¡Dichosa la mujer que así comprenda y acierte a llenar sus deberes! ¡Dichosa la familia que cuente en su seno mujeres semejantes! (García Balmaseda, 1860ª 3)

En otras palabras, bajo una perspectiva cristiana, el que toda mujer esté destinada en el cumplimiento de sus obligaciones morales y religiosas $-\mathrm{O}$ sea, de los deberes de esposa y de madre-, obedece a la asunción y respeto de las cualidades físicas, psicológicas y emocionales que Dios le ha concedido.

En 1860, Joaquina García Balmaseda inauguró la Biblioteca del Correo de la Moda con un Álbum de señoritas, que era un tratado sobre frivolité, punto de media, ganchillo y bordado. Una versión actualizada salió a la luz en 1876 bajo el título de La mujer laboriosa. En ellos pretendía, una vez más, unir entretenimiento y utilidad: familiarizar a la niña con las labores, guiar a la mujer en el conocimiento de aquellas que ignore, y «excitar en todas la laboriosidad y afición al trabajo, base de las virtudes domésticas de la mujer» (García Balmaseda, 1860b: 6), o simplemente, ayudar a su lectora a encontrar «su recreo en la confección de prendas útiles o de adornos de inestimable valor; completando la bella misión que Dios le ha dado en la tierra» (García Balmaseda, 1876: 5).

No sólo instruía Doña Joaquina prodigando conocimientos enciclopédicos o domésticos; al dato aportado le solía acompañar la exégesis moral o religiosa. Hasta en los zurcidos, en la cocina o la intendencia casera, por ejemplo, debía encontrar la joven inquieta, descuidada o poco amante de las tareas domésticas, sabios y prudentes consejos para dar sentido a cada gesto, acto y decisión en aras a la asunción del modelo de mujer y madre ángeles del hogar. Esas displicentes e incluso «descarriadas» eran las que interesaron sobremanera a la escritora y a las que apelaba, valga como botón de muestra, desde las hojas de La Educanda para que aprendiesen a bordar y coser:

Las que no han sabido encontrar dentro de su propio corazón ese germen fecundo de alegrías dulces y tranquilas, como todas las que Dios se dignó conceder a la mujer, que se tomen el trabajo de seguirnos cualquiera de estas noches a primera hora... No temáis, no vamos a conduciros lejos de vuestras casas: por fortuna el espectáculo que queremos mostraros tiene lugar en casi todas aquellas donde se rinde culto a las buenas costumbres, y estas predominan en nuestra patria, a despecho de los que se empeñan en afirmar lo contrario.

Seguidnos...penetrad en el santuario de la familia... (García Balmaseda, 8 de diciembre de 1862: 7). 
Es evidente que a través de estos mensajes, sirva la cita reproducida de testimonio, se iba dignificando todo el elenco de valores de la burguesía conservadora, desde la justificación del papel de la mujer en las esferas privadas del hogar hasta los valores patrios, si bien, insistamos, no de manera exclusiva, pero todavía sin la seguridad o la libertad con las que doña Joaquina se expresó avanzados los años 70 .

Joaquina García Balmaseda, consciente de llenar un vacío editorial en España, siempre hizo alarde de los estudios y el trabajo de documentación, incluso internacional, que solía realizar antes de escribir sus textos para suplir con el estudio sus personales limitaciones ${ }^{5}$. Ella asumía la superioridad de los modelos masculinos en estos ámbitos. Solía utilizar el tópico del áurea mediocritas y tomaba sus prevenciones apelando a la indulgencia de las autoridades varoniles y al reconocimiento de sus lectoras no tanto por la factura de sus obras o la originalidad de su pensamiento -la excelencia se atribuía sistemáticamente a los varones, mejor instruidos-, sino por la utilidad de sus textos y la connivencia que la autora intentaba crear con los infravalorados lectores femeninos e infantiles:

Si a pesar de todo no logro hacer una obra que merezca el elogio del filósofo y el crítico, al menos vosotras, las que presentáis la frente doblemente orlada con el lauro de esposas virtuosas y madres cristianas; vosotras, las que vivís olvidadas de los placeres del mundo por velar el sueño de vuestro hijo y dirigir sus menores pasos, acogeréis mi libro (García Balmaseda, 1860b: 6).

¿Hasta qué punto estaba respondiendo doña Joaquina a las expectativas de sus lectores? ¿Hasta que punto, como otras escritoras, hizo uso de la modestia retórica? La adopción de un sermo humilis, la elección de un tono amistoso y confidencial, la alternancia entre el discurso instructivo y educador con escenas y diálogos ficticios a modo de exempla y la sencillez expresiva muestran cómo la periodista manejaba con acierto el arte de enseñar y el arte de contar. De manera reiterada, en sus artículos periodísticos y en sus prólogos solicitaba la benevolencia del lector, justificando en numerosas ocasiones, el carácter pragmático de sus textos:

No le pidáis, pues, amenidad en el estilo, atildamiento en la frase, interés en la materia... No le tendrá más que para aquellas lectoras que tengan afición a las labores de su sexo; y aun esas habrán de dispensar si sacrificio la belleza

5. Entre sus declaraciones de intenciones, escribía Joaquina García Balmaseda: «Noble es mi propósito, y a fin de realizarlo consultaré cuanto se haya escrito sobre tan importante materia en España y en otros países, donde la Biblioteca de la Infancia posee joyas de gran valor tomando de ellas lo que me parezca más digno de darse a conocer y enlazándolo a mis propias ideas (García Balmaseda, 1860: 6). 
de la forma a la claridad de los detalles. Este libro es de utilidad, y como antes digo, rara vez en la vida se unen la utilidad y el recreo: este libro viene a reemplazar a la amiga, a quien hay necesidad de molestar para que nos enseñe una labro nueva, y facilitara la reproducción de los infinitos modelos que ofrecen de continuo los adelantos modernos; él será un auxilio 'util, en muchos casos necesario, y él contribuirá a desarrollar la afición a esas labores delicadas, que aprendidas a veces en la prosperidad, se utilizan en la desgracia (García Balmaseda, 1873: 7).

Porque la escritora subordinaba la belleza estilística a la eficacia comunicativa, estaba aceptando una mediocridad que no siempre tenía que ver con la incapacidad creativa; sus obras de teatro, por ejemplo, así lo demuestran. Doña Joaquina anteponía su abnegación y su compromiso social para mejorar la condición de las mujeres de las clases bajas y de las familias, células de la sociedad:

Si después de terminar tan penosa y árida tarea, las señoras que lean estas páginas, logran instruirse o perfeccionarse en algún género de labor que les sea desconocido; si otras indolentes adquieren alguna afición a ellas, se verán recompensados mis esfuerzos, y mientras otras escritoras alcanzan lauros por sus obras literarias, consolárame la idea de haber contribuido con un pequeñísimo grano de arena al bienestar de las clases trabajadoras y a la prosperidad de la familia (García Balmaseda, 1873: 7-8).

Durante estos primeros años de actividad literaria, el conocimiento práctico de la actividad teatral y la valoración de su capacidad educativa le incitaron a componer varias piezas dramáticas en un acto, en prosa o en verso. Antes de darlas al gran público, doña Joaquina las estrenó en esferas privadas. En el teatro que el escultor Piquer, uno de sus amigos íntimos, había construido en su propia casa, en los números 30 y 32 de la calle de Leganitos, representó por vez primera el proverbio en un acto, Genio y figura. Ella misma encarnó el papel principal (Cambronero, octubre de 1913: 53). En enero de 1861 obtuvo la autorización de la Censura, por lo que dio a conocer su obra al gran público, en abril de 1861 en el Teatro del Príncipe ${ }^{6}$, y en octubre en el Variedades.

Al parecer, llevó a las tablas del Teatro de la Zarzuela Una escapatoria, según anunciaron la «Revista de Teatros» de La Época y La Libertad en mayo de 1865. Se trataba de una zarzuela en un acto, el público aplaudió algunas

6. Balmaseda escribió esta obra en honor a Teodora Lamadrid, quien representó el papel protagonista junto con Delgado. Genio y Figura era una obrita, describía el cronista de acertada factura, «llena de gracia, sencilla en su plan, pero hábilmente desempeñada en sus caracteres, en su desarrollo dramático y en su desenlace» (7 de abril de 1861: 3.). Asimismo se llevó a escena en el Teatro de la Princesa de Valencia «obteniendo los mayores aplausos del público» (29 de octubre de 1861: 1).

Anales, 23, 2011, pp. 381-403 
escenas y llamó a la escritora, quien estaba ausente (Arderius, 5 de mayo de 1865: 3). Su siguiente estreno se verificó con otro proverbio en un acto y en verso Donde las dan... en Teatro Apolo en 1868.

Los dos proverbios conservados arrojan luz sobre el concepto que doña Joaquina tenía del teatro como escuela de costumbres y del individuo como ser perfectible. Genio y figura... no es una obra que esté escrita como alegato feminista, ni mucho menos. Balmaseda propone una lección moral que las jóvenes maleducadas de las clases pudientes tenían que aprender, e indirectamente, los padres, quienes, a juicio de la escritora, tenían la responsabilidad de guiar a sus hijas en la elección del marido. "Pero tú, hija mía, ya sabes lo que te he dicho: si no te parece bien... si encuentras en él algún defecto... (...) ¡Nada de sacrificios! ¡Nada de violencia!» (García Balmaseda, 1861: 6-7), aconsejaba don Serapio a su hija Carlota, casadera, caprichosa y violenta. No es que la dramaturga hiciese recaer sobre ella todo lo negativo; Rafael, su novio, tenía un carácter también hosco y brusco. La moraleja del proverbio versaba en la necesidad de que los novios aprendan «a conocerse tal cual somos» y «no por eso nos apreciaremos menos» (García Balmaseda, 1861: 24), y la de vivir en armonía con las cualidades que Dios ha dado a cada sexo. Carlota cierra la obra remachando en una décima la lección moral frente al fatalista saber que «genio y figura... »encierra:

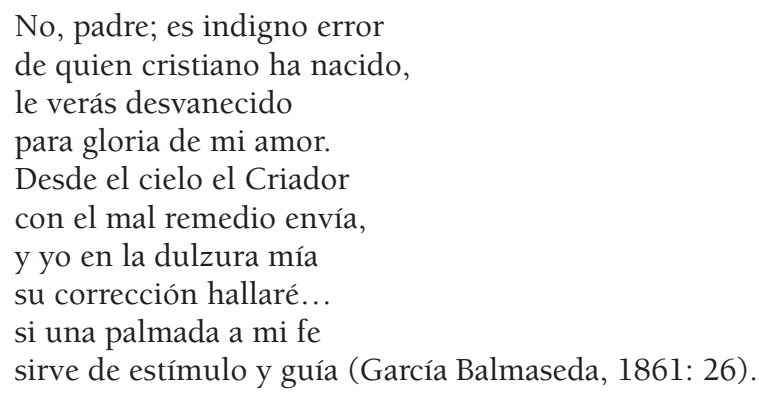

La representación Donde las dan... fue autorizada por el censor José Serra en 1868. En este proverbio, Balmaseda da vida escénica a algunas de sus opiniones sobre de la independencia y la libertad de la mujer. La protagonista, una viuda rica, llamada simbólicamente Victoria, castiga a su novio, Luis, por haber intentado seducirla por error, pensando que era otra persona. Para ello se disfraza de anciana y urde una trampa con la que conseguirá que Luis se arrepienta. La dramaturga subraya ante todo el carácter fuerte e independiente de Victoria, quien había sabido corregir los vicios de Luis al mismo tiempo que sucumbía a sus encantos. El final, siendo un proverbio y en aquella época, no podía ser otro que el canónicamente feliz; o sea, el del matrimonio. 
Tras todas estas primeras y variadas publicaciones periodísticas, pedagógicas y literarias se le abrieron a la «modesta y distinguida escritora» (29 de octubre de 1861: 1) las puertas de otras empresas de mayor envergadura.

A partir de los años 70, Joaquina García Balmaseda colaboró de manera bastante esporádica en numerosas publicaciones periódicas, una media de dos o tres contribuciones -composiciones poéticas en su mayoría- por manchete: La Voz de la Caridad (1872), El Amigo de las Damas (1873), La Madre de Familia (1875), La Familia (1875-1877), Los Niños (1876), La Ilustración de la infancia (1877), El Eco de Europa (1877), La Academia (1878), La Ilustración de los Niños (1879), La Niñez (1880), La Crónica musical (1881-1882), La Aurora de la vida (1882), París-Charmant-Artístico (1882), La Semana Madrileña (1883), Flores y Perlas (1883). Según informaba el periodista de Barcelona Cómica, «su firma se cotiza en el mercado literario al elevado precio que alcanzan las de primera línea» (C. B., 10 de marzo de 1894), por lo que es de suponer que esas colaboraciones fueron puntuales encargos. Fue entonces cuando empezó una etapa decisiva en su carrera, al suceder, en octubre de 1883, a su amiga Ángela Grassi como directora de El Correo de la Moda en el había ido ya colaborando. Ocupó dicho cargo hasta el 26 de diciembre de $1893^{7}$, sin por ello abandonar completamente sus polifacéticas actividades. En este período, la escritora, «con sus obras sucesivas, ha conquistado otro público acaso menos numeroso, pero sin acaso también más distinguido» explicaba la sección «Mujeres ilustres» de Barcelona Cómica (C. B., 3 de octubre de 1894: 14). Así tuvo que suceder cuando publicó uno de sus manuales, a nuestro juicio más interesante y completo, La mujer sensata (1882), obra que fue galardonada en el Congreso pedagógico de 1883. Como reza el subtítulo, esta antología de textos periodísticos se dirigía a un público femenino ya maduro. Doña Joaquina proponía a sus lectoras consejos útiles y leyendas morales para que pudiesen educarse a sí mismas y a sus propios hijos. Como el resto del corpus de la escritora, la obra se basaba en el concepto de perfectibilidad del ser humano en aras a su felicidad y la de los seres que la rodean desde una perspectiva cristiana. En su prólogo, el programa es canónico. La mujer sensata, o lo que es lo mismo, sus numerosos artículos en la prensa, estaban escritos para que la mujer -resaltemos la naturaleza genérica del término-, si es educada «encuentre en su propia docilidad e instrucción el secreto de su dicha hasta donde puedan permitirlo el carácter y las circunstancias que la rodeen»

7. Fundaba su retirada en motivos de salud» (La Correspondencia de España, 26 diciembre 1893: 3). En realidad, El Correo de la Moda desapareció del estadio de la prensa, después de 43 años de existencia, por fallecimiento de su propietario, el conocido editor D. Juan Muñoz Sánchez. 
(García Balmaseda, 1882: 6). Su libro se dirigía a todas las mujeres, para que compartieran la sagrada misión de «dulzura y paz en la familia». Para ello, la escritora se proponía:

Buscar a la mujer en el seno de su hogar, en la vulgaridad de sus faenas domésticas, en la santidad de sus deberes de esposa y madre, como el amigo prudente que señala males y previene consejos; buscar a la mujer poco conforme con su suerte, para que en su propia resignación encuentre la compensación de sus males (García Balmaseda, 1882: 6).

La obra proyectaba su educación integral: religiosa (virtudes), moral (respetabilidad), física (salud, alimentación, higiene) y económica (administración de la fortuna, orden de la casa y bienestar). Con este programa la mujer instruida llegaría a ser modesta, prudente, resignada y de buen carácter. Porque el carácter natural de la mujer, según el canon neocatólico dominante en el pensamiento de doña Joaquina, «la hace ser dulce, caritativa y creyente» (García Balmaseda, 1882: 35), tiene que aprender a aceptar el natural deseo de agradar sin incurrir en la coquetería ni en la vanidad, a actuar con juicio y responsabilidad ante el gasto y el lujo, a no dejarse esclavizar por la moda, a no incurrir en calumnias ni maledicencias, verdadero "pasatiempo en el mundo» (García Balmaseda, 1882: 32), sobre todo cuando no se tiene conversación; pero asimismo tiene que «tener el valor de mostrar sus impresiones cuando no son malas» y de no engañar a los demás ocultando sus defectos (García Balmaseda, 1882: 35- 36). Saber dar ejemplo, enseñar a ser tanto caritativa, como fuerte y valerosa, a elegir las amistades y al compañero de la vida, a cumplir las obligaciones del matrimonio, a respetar la soltería, la belleza de la inteligencia y de la honradez, son responsabilidades que la madre debe asumir para con sus hijas.

Con este programa moral y la riqueza incondicional de la instrucción a lo largo de toda la vida, la mujer podría encontrar, a juicio de la escritora, el justo medio entre sus derechos y deberes, distanciándose de la «autómata» mojigata de tiempos pasados, porque:

Hoy, por el contrario, no se considera un peligro que la mujer aprenda, lea o discuta, pero no se cuida de ilustrar su razón en el buen sentido; no se la enseña a emplear con acierto sus facultades, ni se la hace comprender su verdadera significación y destino: en otros tiempo se la tiranizaba sin otorgarle voluntad propia, hoy se la deja la responsabilidad de sus actos, sin enseñarle a cumplirlos. ¿Cómo atreverse a condenarla el día que no los cumple bien? (...)

Queréis que, como en otro tiempo, la mujer tenga una limitada inteligencia, no porque la naturaleza se la negara, que pródiga estuvo por fortuna en este terreno con la mujer, y aún los detractores de nuestro sexo no han podido negarle una sagacidad, una viveza de comprensión, con la que en 
vano procuran rivalizar el entendimiento claro, el estudio perseverante del hombre, sino porque viendo en cada libro un peligro, en cada papel escrito por ella un motivo de perdición, se le daba voluntad para no querer, inteligencia para no pensar, personalidad para destruirla y pies para no moverse (García Balmaseda, 1882: 64).

Para la escritora, la mujer tenía que dejar de ser esclava, pero, sin por ello incurrir en los extremismos de los reformadores «que la quieren libre hasta la excentricidad» (García Balmaseda, 1882: 65) ya que querían que abandonasen sus deberes para usurpar los derechos del hombre. Aun cuando el modelo doméstico fuese el defendido por la escritora, aun cuando reclamase independencia y capacidad de gestión para todas, y carreras y oficios dignos -comerciante, contable, bibliotecaria, telegrafista, maestra, médico, pintora, escritora, actriz- para las que lo deseaban o necesitan, pensaba que los derechos fuera de la familia no «se ajustan siempre a las condiciones de cada individuo; la conciencia de los deberes arranca de la vida práctica, de las situaciones especiales de cada familia, y el modo de cumplirlos se refleja en el bienestar de cada una» (García Balmaseda, 1882: 67). Pese a los aplausos, los honores y las amarguras de la vida pública, Balmaseda estaba convencida de que éstos no valían «la sonrisa de vuestro hijo cuando al despertar os tiende sus brazos, ni el placer de endulzar a vuestro compañero las amarguras (García Balmaseda, 1882: 66).

Para el hogar o fuera de él, para ser buena compañera y madre o para 'tener un porvenir más lisonjero que ganar una o dos pesetas al día inclinada sobre una máquina de costura» (García Balmaseda, 1882: 87) lo primordial era, a juicio de la escritora, que la mujer adquiriese la instrucción necesaria. No era el renombre de los círculos eruditos ni el brillo en ellos -como ocurrió en célebre caso de Rosario Acuña en el Ateneo (Sánchez Llama, 2001: 235-236)-, lo que se tenía que perseguir, sino la de mejorar la condición de la mujer, tanto más en cuanto que las misiones legítimas de esposa, madre e hija no eran las únicas:

$¿$ No hay muchas que por razones propias o ajenas conservan su independencia, su personalidad? ¿Por qué no se la ha de ayudar a conservarla dignamente? (...)

¿No hemos visto infinitas mujeres, músicas, pintoras, actrices, acostumbradas a vivir entre lisonjas y aplausos, retirase de la vida pública el día que han sido esposas y madres, siéndolo de una manera ejemplar? Otro tanto sucederá con los demás estudios: por cada mujer doctora o marisabidilla darán cien esposas instruidas, cien madres capaces de dirigir a sus hijos, y no pocas mujeres que podrán conservar su honrosa independencia sin sacrificarse a un consorcio, que tienen aceptar las más veces por necesidad y no por amor. 
La mujer no puede ser más que casada y dependiente de otro ser, ¿qué culpa tiene al aceptar con violencia la servidumbre? (García Balmaseda, 1882: 90).

Puesto que un marido no siempre asegura el porvenir de la mujer, Joaquina García Balmaseda instaba a los padres a que diesen a sus hijos, sin distinción de sexo, igual derecho a la educación.

Estas ideas sobre la cuestión femenina dan vida al resto de la creación de doña Joaquina en este periodo. A diferencia de los escritos para mujeres de las clases trabajadoras, su libro de utilidad y recreo para las niñas, Historia de una muñeca (1889) estaba compuesto para las niñas de las pudientes clases burguesas. Porque el mimetismo con el que se juega a la muñeca favorecía, según la escritora, un saludable aprendizaje, compuso para sus infantiles lectoras las novelescas aventuras de una muñeca, las cuales sirven de pretexto para incrementar su instrucción y educación moral.

De esta época destacan asimismo algunas creaciones teatrales breves: las comedias en prosa Un pájaro en el garlito y La última distracción, ésta estrenada en el Teatro de las Variedades el 8 de febrero de 1874 pero sin localizar, junto con el cuadro original en verso titulado El ángel del hogar. Dicho cuadro sólo se llevó a escena en fiestas privadas, al menos, en la casa del comandante Keller, familia amiga de la escritora («Noticias», La Época, 8 de junio de 1879: 3), para cuyas hijas, Gloria y Stella, lo compuso en 1888 (1 de abril 1888: 3). Fue impresa en Barcelona muchos años después, en 1913, tal vez al representado en la Escuela Nacional de Música y Declamación.

En las dos obras localizadas, Un pájaro en el garlito y El ángel del hogar, la mujer sigue siendo el tema principal. En el primero, los alardes de libertad e independencia de la viuda joven y rica son canalizados una vez más hacia la solución matrimonial. Los análisis propuestos por Ermanno Caldera y por David Gies subrayan la actualidad y simpatía del personaje de Rosario, en cuyo perfil plasma la dramaturga sus propias convicciones, consciente tal vez, como anotaba Caldera de «la dificultad de realizar el programa anunciado por Rosario en un medio ambiente dominado por hombres insolentes y chocarreros» (Caldera, 1990: 210-211).

Las ideas de la actriz sobre la superioridad de la mujer respecto del hombre nutren el cuadro original El ángel del hogar. Con tres personajes, dos niñas, Elena y Juanita, y su abuelo Don Juan, Balmaseda plantea el tema de la desigualdad entre sexos para demostrar la superioridad del femenino. La obra se construye en torno al engaño en que vive el abuelo creyendo que tiene un

8. Entre los ecos de sociedad del 7 de junio de 1897, La Correspondencia de España notificaba su representación en el teatro privado de Isidoro de Arcos. 
nieto en Manila -en realidad Juanita- ya que se proyecta en él como futuro garante de la tradición familiar y además sueña en encontrar en él al nieto cariñoso a quién mimar y transmitir su saber. «iCuando sepa que su Juan/ se ha convertido en Juanita!» exclamaba Elena, la nieta que con él vivía en Madrid, en aparte, burlándose del abuelo (García Balmaseda, 1913: 10). La dramaturga perfila a Elena con los rasgos del propio abuelo. A ella le divierten sus andanzas e historias militares, es descarada y revoltosa, vicios que hubiesen sido virtudes bajo una piel varonil, pero que cansaban al abuelo. Pero como bien expresaba Elena:

Yo quisiera ser chiquillo, pero abuelito en razón.

Yo la culpa no he tenido, solo Dios, que no ha querido que yo naciera varón. Si lo fuera ¡Dios Bendito! Yo sería general (García Balmaseda,1913: 11).

Cuando Juanita llega de Manila, en vez del esperado nieto el abuelo descubre las cualidades de una púber angelical. Juanita le desvela la verdad y sabe, con sus cualidades femeninas, convertirse en remanso de paz para Don Juan:

Ven acá niña hechicera

a ser desde hoy hija mía.

Fuera locura sin tasa

querer un chico, él sería

buen general algún día,

tú, jalegría de la casa!

Ven pues la mía a encantar,

pues Dios en ella me encierra,

y en vez de rayo en la guerra

serás ¡Ángel de mi hogar! (García Balmaseda, 1913: 20)

La última distracción gozó de calurosa acogida de los espectadores. Al decir de gacetillero, el público «no cesó de celebrar el chispeante diálogo y bellas situaciones de la obra, así como la esmerada ejecución de los actores» (8 de febrero de 1874: 3; Eduardo de Cortázar, 1874: 130). Otros títulos que no hemos podido documentar son Reo y Juez y Lo que no compra el dinero (Huerta Posada, 14 de junio de 1896: 9).

A partir de 1894 con el cierre de El Correo de la Moda y las sucesivas estancias de la escritora en Burgos y Salamanca, su firma fue haciéndose cada vez más esporádica en la prensa: Andalucía (1895) y Barcelona Cómica (1895), Pro-patria (1895), La Moda Europea (1899), El Heraldo de Madrid (1896), El Oriente de Asturias (1899-1900), Gente Vieja (1904) y El Álbum 
Hispano-Americano (1906) fueron algunos de las cabeceras que acogieron esporádicamente sus textos.

A Joaquina García Balmaseda, o a Aurora Pérez Mirón (seudónimo tras el que se escudaba en El Correo de la Moda), La Correspondencia de España las convirtió desde muy temprano en noticia. No por nada aquel Diario universal de la noticia contó con una fiel y eficaz periodista y traductora. Al lector se le iba informando de sus estancias fuera de la Corte en periodos vacacionales y sobre algunos acontecimientos de su vida pública y privada. Cierto es que la proyección pública de Joaquina García Balmaseda fue amplia, su vida social activa. Formaba además parte de algunos círculos literarios y artísticos madrileños, participaba en acciones benéficas, homenajes, lecturas y veladas literarias en los que siempre sobresalía, gustaba reseñar La Correspondencia de España, por su natural simpatía y sus cualidades literarias. Dirigió la Sección de Labores del efímero Ateneo de Señoras (Sáenz de Melgar, 1869: 15) y según notificaba La Época, en junio de 1897, fue la primera dama que ocupó la tribuna del Paraninfo de la Universidad Central. En realidad, este hecho verídico, que se suele mentar como singular evento, transcurrió al margen de la vida académica universitaria, en un acto circunstancial, ya que allí leyó, ante un escogido público, su poema de circunstancia «Aves y Flores» «en la solemne distribución de premios concedidos por las Sociedades protectoras de cada una de ellas» (Huerta Posada, 1896: 3, y García Balmaseda, 1907: 77-80).

El Álbum de la señorita $D^{a}$ Joaquina García Balmaseda da cuenta de sus relaciones de sociabilidad, al menos entre 1863 y 1874, fechas entre las que están datados los autógrafos y los dibujos originales que lo componen y que ella misma fue recogiendo. La mayoría de ellos provienen de escritores relevantes. Lo abre un poema "A Joaquinita», de Juan Eugenio de Hartzenbusch, y como él, la mayoría compusieron poesías encomiásticas en honor a la propietaria, destacando su belleza, su inspiración y habilidad como escritora, así como sus grandes cualidades personales. Del carácter personal y directo, así como del tono amistoso de los autógrafos, se puede inferir que la poetisa gozaba ya en 1863 de notable reconocimiento en los círculos artísticos y teatrales de la capital. Ramón de Campoamor, Antonio Fernández Grilo, Gaspar Núñez de Arce, Ventura de la Vega, Ángel María Dacarrete, Adelardo López de Ayala, Manuel del Palacio, Luis Vidart, Luis Mariano de Larra, Manuel Cañete, Narciso Serra y Manuel Bretón de los Herreros y Eusebio Blasco, entre otros, cedieron su pluma para éste Álbum. Solo tres escritoras colaboraron en él: Ángela Grassi, Josefina Alcalá y Amalia Domingo. Entre los pintores, valga citar los nombres de Concepción Malpica y de Joaquín Espalter. 
Otro testimonio de la presencia activa de Balmaseda en esas redes literarias y sociales lo ofrecen los volúmenes colectivos y los homenajes en los que participó, entre los que cabría mencionar, como botón de muestra, Libro de la Caridad, publicado en 1879, a expensas de Alfonso XII, para socorrer a las victimas de la inundación en Levante, Corona poética dedicada a la memoria de Bretón de los Herreros (1875), Corona Poética en honor del esclarecido poeta D. Gabriel García Tassara (1878), El Curioso parlante (1892), un álbum en honor a la memoria de Mesoneros Romanos, así como en las poesías dedicadas a la realeza en celebraciones y coronas fúnebres localizadas por María del Carmen Simón Palmer (Simón Palmer, 1991: 292 y Ramírez Gómez, 2000: 159)9.

Pese a esa vida de troquel burgués y conservador, Joaquina García Balmaseda manifestaba en su autorretrato que:

La luz del día vi en modesto hogar

Y hube de trabajar para vivir,

Mas tal carga jamás me hizo sufrir

Y en más de una ocasión me hizo brillar (García Balmaseda, 1907: 207).

«Trabajar para vivir», como modo y medio de vida de una mujer, no respondía precisamente a los patrones de la buena sociedad decimonónica. Sin embargo, como desvelaba el cuarteto reproducido, Joaquina García Balmaseda encarnaba el modelo de mujer independiente, que consiguió franquear las barreras de las cerradas esferas públicas.

Pasar del mundo de la farándula al de la literatura impresa moral y didáctica, de ser actriz a prestigiosa escritora en poco menos de cinco años (de 1855 a 1860) y, además, siendo mujer soltera descendiendo de un «modesto hogar»; todo ello enmarca a la escritora en la escala de la ascensión y del progreso sociales merced al esfuerzo, al estudio y al trabajo constante. Por sus vivencias, forzosas o no, García Balmaseda encarnó a la mujer emancipada. En ello, influyó pertinazmente su larga soltería, estado en el que la mujer podía encontrar socialmente relativo margen de libertad, al menos, mayor que el de las casadas.

A la sombra de la Baronesa de Olivares, Aurora Pérez Mirón ${ }^{10}$, Adela Samb, Agua de Valldaura y Zahara («Unos cuantos seudónimos españoles»,

9. En 1882 participó en el «Certamen literario de poetisas españolas» de Alba de Tormes en el Tercer centenario de Santa Teresa de Jesús y su poesía fue galardonada. La misma escritora recogió todas estas poesías en su libro Ecos del día (1907).

10. Aurora Pérez Mirón fue la cronista de modas «más autorizada», según la «Revista de Modas» de La Correspondencia de España en 1868. Su crónica era comentada y resumida en numerosos periódicos, tales como La Iberia, La Época, La Discusión, La Educanda o La España. 
1892: 362 y ss.), Joaquina García Balmaseda fue perpetuando su nombradía. Hubiera «dado cualquier cosa por pertenecer a la aristocracia», deducía Simón Palmer por haber adoptado un título como seudónimo (Simón Palmer, 1989: 91), en un Madrid ecléctico, ya relativamente movedizo, «donde todas las clases se revuelven en confusa amalgama», constataba la escritora (García Balmaseda, [1881b]: 263). Otros aspectos ya mencionados como la constitución de un álbum personal de autógrafos, su incondicional presencia en el mundo cultural de signo conservador y su especialización en el ámbito de la moda fueron probablemente emblemas de su afán por apuntalar su ascensión social, su pertenencia a la burguesía y el goce de cierta popularidad.

Si bien fue una escritora humilde y ferviente religiosa, solía actuar con clarividencia para responder a la finalidad práctica de los textos que componía, a las exigencias de respeto al dogma católico y la sana moral de la Censura eclesiástica, y en última instancia, a las expectativas de su público lector. En la coyuntura en que escribió, como profesional de la pluma, fue una mujer fuerte, como aquella mujer artista que ella misma fue y sobre la que escribía en Las españolas pintadas por sí mismas: " $\mathrm{iA}$ un alma de artista la lucha la arrastra, los obstáculos la empeñan, el entusiasmo la impulsa, y cuando logra derribando obstáculos y allanando dificultades un rayo de gloria para su frente, juzga bien empleadas todas sus amarguras, todas su febriles luchas! (García Balmaseda, [1881]:75). De hecho, apoyándose en su experiencia personal y en autores moralistas franceses como Ernest Legouvé, defensores de la cuestión femenina, Doña Joaquina intentó inculcar desde la prensa que la mujer valía por sí misma y tenía que ocupar un lugar digno en la sociedad.

Ella, que pergeñó en convencer a madres y a jóvenes de que «que no era una desgracia quedarse soltera» y que en el «estado de soltera vieja hay tanta dignidad y valer como en cualquier otra situación de la vida» (García Balmaseda, 1882: 59), contrajo matrimonio a los cuarenta y seis años de edad con el comandante Eustaquio González Marcos, el 2 de marzo de 1883, en la parroquia de Santiago de Madrid. Él era profesor de veterinaria del regimiento de Húsares de Pavía y escritor en periódicos militares. Desde entonces, doña Joaquina firmó sólo como Balmaseda de González, asumiendo el papel tradicional de esposa, «honrada y leal compañera» (García Balmaseda, 1882: 56), pero sin por ello abandonar su cargo de directora de El Correo de la Moda ni sus múltiples actividades. A partir de 1894, tras el cierre de dicho periódico, fue limitando paulatinamente la creación literaria hasta los albores del siglo XX. En 1900, precisamente confesaba: «mas no diera hoy mi razón/ Por la vida halagüeña que perdí,/ ¡La venturosa paz de mi rincón!» (García Balmaseda, 1907: 207). 
En 1907, Doña Joaquina, quien tantos consejos prodigó sobre el comportamiento y las cualidades morales de la esposa, quedó viuda ( 5 de septiembre de 1907: 3). Ese año compiló un número importante de poesías que publicó en memoria de su marido bajo el título Ecos de otra edad (1907). Como notificaba el periódico, «aunque por mucho tiempo ha permanecido Joaquina Balmaseda alejada de las lídes literarias, no la había olvidado el público» (7 de octubre de 1906: 9).

En los trabajos que hasta la fecha se la han dedicado y en diferentes repertorios, literarios o bibliográficos, se suele proponer y repetir 1893 como fecha del óbito de Joaquina García Balmaseda; esa fecha es sin embargo errónea. El 19 de febrero de aquel año, las noticias de La Correspondencia de España y de La Época lo confirman, la que en realidad falleció fue la madre de la escritora, Francisca Balmaseda y Olivares (de quien se inspiró para otro de sus seudónimos, Baronesa de Olivares). A Doña Joaquina la muerte no le sobrevino hasta el 2 de marzo de 1911 (La Época, 3 de marzo de 1911: 3; La Correspondencia de España, 3 de marzo de 1911: 1).

En su trayectoria literaria y ensayística, Joaquina García Balmaseda conjugó dos facetas literarias distintas: la pedagógica, con artículos y manuales destinados a la mujer con fines pragmáticos directos, junto con la creativa, orientada a la ficción y el lirismo con narraciones, poesías y obras teatrales. Ambas comparten como eje vertebrador la cuestión femenina y se ubican o construyen universos en la que la mujer puede acaparar el tema, la trama, el argumento y perfilar los personajes principales; en suma, relega al hombre y al mundo masculino a un segundo plano, a ser personajes secundarios, e incluso en sus manuales, a meras abstracciones silentes. Si doña Joaquina concedía a la mujer todo protagonismo era porque siempre prefirió sus proyectos pedagógicos a favor de una instrucción útil y de una educación moral de la mujer. De la integridad moral, de la fuerza el carácter, de su instrucción dependerían los derroteros que tomaría su vida, comúnmente dentro del hogar, de manera singular, en las esferas públicas. La mujer, para doña Joaquina, podía ser un perfecto ángel del hogar y una buena profesional, independientemente de su clase social.

Tanto los textos de creación artística, como los ensayos y artículos didácticos o de opinión son alegatos de las normas y valores de los códigos moralizantes del neocatolicismo imperante (Sánchez Llamas, Alda Blanco). En ellos, la escritora va introduciendo algunos cambios, moderados pero significativos, a partir de un feminismo social que exige la educación de la mujer, para encumbrar su papel como pilar de la felicidad familiar, pero asimismo, 
para otorgar mayor independencia y mejores condiciones laborales si a estas tiene que recurrir.

El estudio de los numerosos artículos de la escritora en su contexto, sin miradas de presente, podrá demostrar que las contradicciones feministas que se le achacan (Smith, 2009) no lo son tanto desde una perspectiva a la vez global y diacrónica. Extractar y citar sus textos, sin una mirada de conjunto, puede resultar tendencioso. Por ende, no se puede eludir la propia evolución histórica del ejercicio del derecho de libertad de prensa e imprenta y el grado de severidad de la censura hasta que la ley de imprenta de 1874 (Cendán Pazos, 1974). Si se podía delinquir por medio de la imprenta contra la sociedad, la religión y la moral pública, entre otros, como certifica la aprobación del Licenciado Maniel de Obesso que abre La madre de familia, en 1860, o las de sus obras de teatro ya citadas, ¿cómo obviar el peso que la censura pudo ejercer sobre la autocensura en los escritores? Este no fue ni determinante ni exclusivo en el caso de García Balmaseda, ya que sobre ella influyeron asimismo, su ascendencia social, su larga soltería, entre otros factores socioculturales como la negativa consideración a la mujer trabajadora, el concepto de respetabilidad y el mismo conformismo de las clases dominantes en materia de moralidad. A pesar de ello, como se ha podido ir observando, la escritora siguió una línea de pensamiento coherente en toda su trayectoria, lo que evolucionó, fue la libertad que se concedía en la expresión más abierta y directa de sus ideas a partir de mediados de los 70. Los tiempos eran distintos y ella una mujer en las puertas de la senectud. ¿Podría haber escrito en 1860 en la prensa lo que publicó en libro diecisiete años después? Se hubiese incluso socialmente tolerado a una joven colaboradora de la prensa conservadora advertir a las mujeres que:

las facultades que Dios nos otorga, no son propias para un sólo estado; en todos podemos emplearlas con aprovechamiento propio y ajeno (...) No incurras en el error, amiga querida, de creer que el matrimonio es indispensable para la mujer, vulgaridad que ha dado origen a uniones bien desdichadas: el matrimonio ni es necesario a la dicha, ni la ofrece siempre... (García Balmaseda, 1877: 105).

A través del itinerario aquí esbozado se puede constatar que por su dedicación constante al mundo de las Letras, por su inagotable y extensa labor, Joaquina García Balmaseda merecería estudios de conjunto y de mayor alcance que el presente. Doña Joaquina logró descollar por ser una escritora profesional capaz de vivir de su pluma, por alcanzar un reconocimiento popular y, según el testimonio de La Correspondencia de España, por haber sido modelo de inspiración, de: 
extraordinaria cultura y exquisito buen gusto. Jamás se olvidó de su sexo al correr de la pluma sobre las cuartillas; siempre fue una gran escritora y una mujer cristiana, cuyo talento se puso constantemente al servicio de toda obra benéfica («Joaquina García Balmaseda», La Correspondencia de España, 3 de marzo de 1911: 1).

\section{BIBLIOGRAFÍA}

«Edición de la mañana», La Correspondencia de España, 7 de abril de 1861, p. 3. «Primera edición», La Correspondencia de España, 29 de octubre de 1861, p. 1. «Tercera edición», La Correspondencia de España, 8 de febrero de 1874, p. 3. «Noticias», La Correspondencia de España, 1 de abril 1888, p. 3.

«Unos cuantos seudónimos españoles con sus correspondientes nombres verdaderos», Revista Contemporánea, julio-agosto 1892, pp. 337-362.

«Noticias», La Correspondencia de España, 26 diciembre 1893, p. 3.

«Noticias», El Álbum Ibero-americano, 7 de octubre de 1906, p. 9.

«Noticias», La Correspondencia de España, 5 de septiembre de 1907, p. 3.

«Noticias generales», La Época, 3 de marzo de 1911, p. 3.

«Joaquina García Balmaseda», La Correspondencia de España, 3 de marzo de 1911, p. 1.

ARDERIUS, 5 de mayo de 1865, «Noticias», La Correspondencia de España, p. 3.

BALMASEDA, Joaquina, «La actriz española», en Faustina Saez de Melgar, Las mujeres españolas, americanas y lusitanas pintadas por sí mismas, Barcelona, Juan Pons, [s.a.].

Blanco, Alda, «Teóricas de la conciencia feminista», en Catherine Jagoe, Alda Blanco y Cristina Enríquez de Salamanca (eds), La mujer en los discursos de género: textos y contextos en el siglo XIX, Madrid, Icaria, 1995, pp. 445-472.

C. B., 10 de marzo de 1894, «Mujeres ilustres», Barcelona Cómica, p. 14.

CALDERA, Ermanno, «La perspectiva femenina en el teatro de Joaquina García Balmaseda y Enriqueta Lozano», en Marina Mayoral (ed.), Escritoras románticas españolas, Madrid, Banco Exterior, 1990, pp. 207-216.

Cambronero, Carlos, «Crónicas del Tiempo de Isabel II». La España Moderna, 298, octubre 1913, p. 53.

CAÑETE, Manuel, «Boletín bibliográfico», Revista de España, 1868, 1, p. 159.

CENDÁN PAZOS, Fernando, Historia del derecho español de prensa e imprenta (15021966), Madrid, Ed. Nacional, 1974, p. 72.

CORTÁzAR, Eduardo de, «Crítica estadístico-teatral», Revista de España, 7, 1874, p. 130.

García Balmaseda, Joaquina, Biblioteca del Correo de la Moda. Álbum de señoritas, Madrid, Imprenta de Miguel Campo Redondo, 1860a.

- La madre de familia. Diálogos instructivos. Madrid. Librería de la Viuda de Hernando, 1860b. 
- Genio y figura, Madrid, Imprenta de José Rodríguez, 1861.

— «Labores», La Educanda, 8 de diciembre de 1862, pp. 6-7.

- Donde las dan..., Proverbio en un acto y en verso, original. Madrid, Establecimiento tipográfico de Eduardo Cuesta, 1868.

- Entre el Cielo y la Tierra. Poesías, precedidas de un prólogo del Sr. D. Manuel Cañete, Madrid, M. Campo-Redondo, 1868.

- Un pájaro en el garlito. Comedia en un acto y en prosa, original, Madrid, José Rodríguez, 1871.

- La mujer laboriosa, novísimo manual de labores que comprende desde los primeros rudimentos de costura hasta las más frívolas labores de adorno, Madrid, [s.n.].

- «La actriz española» en Las mujeres españolas, americanas y lusitanas pintadas por sí mismas, [1881]. Faustina Sáez de Melgar, ed., Alicante, Biblioteca Virtual Miguel de Cervantes, 2006. Reproducción digital de la edición de Barcelona, Juan Pons, pp. 63-77. http://www.cervantesvirtual.com/servlet/SirveObras/01470507689014084197857/index.htm

- La mujer sensata. Educación de sí misma, Madrid, Imprenta de la Correspondencia, 1882.

- Historia de una muñeca escrita por ella misma: libro de utilidad y recreo para las niñas, Barcelona, Libr ${ }^{a}$ de Juan y Antonio Bastinos, 1889.

- Ecos de otra edad, Madrid, Ducazcal, 1907.

- El ángel del hogar, Barcelona, Establecimiento editorial de Antonio J. Bastinos, 1913.

GIES, David «Mujer y dramaturga: conflicto y resolución en el teatro español del siglo XIX», en Del romanticismo al realismo. Actas del I coloquio de la Sociedad de Literatura Española del siglo XIX, Barcelona, Universidad de Barcelona, 1996, pp. 119-129.

Huerta PosADA, Ramón de la, «Escritoras y artistas españolas», El Álbum IberoAmericano, Madrid, 1897.

— «La mujer», El Álbum Ibero-americano, 4 de junio de 1896, p. 9.

Jagoe, Catherine, Alda Blanco y Cristina Enríquez de Salamanca, La mujer en los discursos de género. Textos y contextos en el siglo XIX, Madrid, Icaria, 1995.

KIRKPATRICK, Susan. Las Románticas. Escritoras y subjetividad en España (18351850), Madrid, Cátedra, 1991.

RAMíREZ GÓMEZ, Carmen, Mujeres escritoras en la prensa andaluza del siglo XX (1900-1950), Universidad de Sevilla, 2000.

SÁEnz de Melgar, Faustina, Memoria del Ateneo de Señoras, Madrid, Imprenta de Rojas, 1869.

SÁnCHEZ Llama, Iñigo, Galería de escritoras isabelinas. La prensa periódica entre 1833 y 1895, Madrid, Cátedra, 2000. 
- Antología de la prensa períodica isabelina escrita por mujeres, 1843-1894, Cádiz, Universidad de Cádiz, 2001.

SimÓN PALMER, María del Carmen, «Escritoras españolas del siglo XIX o el miedo a la marginalización», Anales de Literatura Española de la Universidad de Alicante, 2 (1983), pp. 477-490.

- «García Balmaseda, Joaquina», en Escritoras españolas del siglo XIX. Manual bio-bibliográfico, Madrid, Castalia, 1991, pp. 284-293.

— «La ocultación de la propia personalidad en las escritoras del siglo XIX», Actas del IX Congreso de la Asociación Internacional de Hispanistas, Berlín, Frankfurt am Main, Vervuert Verlag, 2, 1989, pp. 91-100.

SINUÉs, Pilar, Epistolario manual para las Señoritas. Modelo de cartas propias para la niña, la joven y la mujer. Epistolario moral literario, Barcelona, [s.n.], 1877.

SMITH, Andrea, «Joaquina García Balmaseda: desconocida dramaturga decimonónica». Stichomythia, 8, 2009, pp. 30-42.

Fecha de recepción: 17/02/2010

Fecha de aceptación: 07/05/2010

Anales, 23, 2011, pp. 381-403 